\title{
Kv1.5 in the immune system: the good, the bad, or the ugly?
}

\author{
Antonio Felipe $^{1 *}$, Concepció Soler $^{2}$ and Núria Comes ${ }^{1}$ \\ 1 Molecular Physiology Laboratory, Departament de Bioquímica i Biologia Molecular, Institut de Biomedicina, Universitat de Barcelona, Barcelona, Spain \\ 2 Departament de Patologia i Terapèutica Experimental, Facultat de Medicina, Campus de Bellvitge, Universitat de Barcelona, Barcelona, Spain
}

\author{
Edited by: \\ Ali Mobasheri, The University of \\ Nottingham, UK \\ Reviewed by: \\ Martyn P. Mahaut-Smith, University of \\ Leicester, UK \\ Richard Barrett-Jolley, University of \\ Liverpool, UK \\ Harley Takatsuna Kurata, University of \\ British Columbia, Canada \\ *Correspondence: \\ Antonio Felipe, Molecular Physiology \\ Laboratory, Departament de \\ Bioquímica i Biologia Molecular, Institut \\ de Biomedicina, Universitat de \\ Barcelona, Avda Diagonal 645, E-08028 \\ Barcelona, Spain \\ e-mail: afelipe@ub.edu
}

For the last 20 years, knowledge of the physiological role of voltage-dependent potassium channels (Kv) in the immune system has grown exponentially. Leukocytes express a limited repertoire of $\mathrm{Kv}$ channels, which contribute to the membrane potential. These proteins are involved in the immune response and are therefore considered good pharmacological targets. Although there is a clear consensus about the physiological relevance of Kv1.3, the expression and the role of Kv1.5 are controversial. However, recent reports indicate that certain heteromeric $\mathrm{Kv} 1.3 / \mathrm{Kv} 1.5$ associations may provide insight on Kv1.5. Here, we summarize what is known about this issue and highlight the role of Kv1.5 partnership interactions that could be responsible for this debate. The Kv1.3/Kv1.5 heterotetrameric composition of the channel and their possible differential associations with accessory regulatory proteins warrant further investigation.

\section{Keywords: leukocytes, potassium channels, association, heterotetramers, channelosome}

\section{$\mathrm{K}^{+}$CHANNELS IN THE IMMUNE SYSTEM}

The immune response is modulated by membrane transduction of extracellular signals. Many interactions occur via the regulation of transmembrane ion fluxes, which govern several signal transduction pathways (Eder, 1998). Thus, immune system cells change their membrane electrophysiological properties depending on their functional state. Changes in membrane potential are among the earliest events occurring upon stimulation or immunosuppression, and ion channels underlie the $\mathrm{Ca}^{2+}$ signal involved in leukocyte responses. In this context, potassium channels indirectly determine the driving force for $\mathrm{Ca}^{2+}$ entry. Several types of $\mathrm{K}^{+}$channels determine the membrane potential, thereby playing a crucial role in cellular excitability. Despite the importance of $\mathrm{K}^{+}$channels in the maintenance of electrogenic driving force for $\mathrm{Ca}^{2+}$ channels, leukocytes express a limited repertoire (Cahalan and Chandy, 1997, 2009; Panyi, et al., 2004). Thus, only the inwardly-rectifying $\mathrm{K}_{\mathrm{ir}} 2.1$, $\mathrm{Ca}^{2+}$-dependent $\mathrm{K}^{+}$channels $\left(\mathrm{K}_{\mathrm{Ca}}\right)$, and some voltage-dependent $\mathrm{K}^{+}$channels (Kv) have been detected in leukocytes (Beeton and Chandy, 2005).

\section{VOLTAGE-DEPENDENT $\mathrm{K}^{+}$CHANNELS}

The voltage-dependent $\mathrm{K}^{+}$channel $(\mathrm{Kv})$ superfamily is the most diverse, numerous, and ubiquitous class of $\mathrm{K}^{+}$channel groups. $\mathrm{Kv}$ channels contribute to the resting membrane potential and control action potentials of excitable cells (Hille, 2001). In addition, they are involved in the activation and proliferation of leukocytes. Accumulating evidence indicates that $\mathrm{Kv}$ channels play a pivotal role in the modulation of immune responses (Beeton and Chandy, 2005; Cahalan and Chandy, 2009).

$\mathrm{Kv}$ channels possess six transmembrane domains and may be further subdivided into twelve conserved gene subfamilies. These subfamilies comprise the voltage-dependent channels Kv1-4 (Shaker, Shab, Shaw, Shal-like subunits), the so-called KCNQ channels
(Kv7), the silent Kv5, Kv6, Kv8, and Kv9 subunits (modulators), and the eag-like channels (Kv10-12). The Kv, KCNQ and eag-like $\mathrm{K}^{+}$channels are typically closed at the resting potential of the excitable cells but open when the membrane is depolarized. They are involved in the repolarization of the action potential and thus in the electrical excitability of nerve and muscle. They also modulate activation, proliferation, and differentiation, especially in leukocytes and myocytes (Hille, 2001). Mutations in the genes encoding members of these $\mathrm{Kv}$ channel subfamilies clearly lead to a number of human diseases, such as episodic ataxia, atrial fibrillation, long QT syndrome and epilepsy (Lehmann-Horn and Jurkat-Rott, 1999; Ashcroft, 2000; Jurkat-Rott et al., 2002, 2010; Gutman et al., 2005; Sanguinetti and Tristani-Firouzi, 2006).

Several Kv isoforms have been found in transformed and nontransformed immune system cells. Although members from the Kv1 subfamily (such as Kv1.1, Kv1.2, Kv1.3, Kv1.5, and Kv1.6) have been detected in primary lymphocytes and macrophages (Pyo et al., 1997; Liu et al., 2002; Vicente et al., 2003), eag-like $\mathrm{K}^{+}$channels (Kv10.1 and Kv11.1) are found in lymphoblastic leukemias and during neoplastic growth (Pillozzi et al., 2002; Smith et al., 2002). Thus, although Kv10.1 (h-eag) is not present in any primary leukemic cells or non-transformed lymphocytes, the channel is upregulated in myelodysplastic syndromes, chronic myeloid leukemia and acute myeloid leukemias (Agarwal et al., 2010). In addition, Kv11.1 (h-erg) is up-regulated in cancer cells but has no correlation with any growth phenotype because it is not elevated in proliferating non-cancerous lymphocytes (Smith et al., 2002).

Kv1.3 is considered the major type responsible for the voltagedependent $\mathrm{K}^{+}$currents in these cells (Rangaraju et al., 2009). Although Kv1.3 channels contribute to the resting membrane potential in immune system cells (Cahalan et al., 1985; Beeton and Chandy, 2005; Cahalan and Chandy, 2009; Krummel and Cahalan, 2010), anion currents compensate in Kv1.3 knock-out 
mice (Koni et al., 2003). However, this protein plays a critical role during activation and proliferation of leukocytes, and several studies point to this channel as an excellent target for immunomodulation (Beeton and Chandy, 2005; Rangaraju et al., 2009). Kv1.3 is abundantly expressed in T-effector memory lymphocytes. These T-cells are key mediators in autoimmune inflammatory diseases, such as multiple sclerosis, rheumatoid arthritis, psoriasis, and type I diabetes, and Kv1.3-based therapies are effective in experimental models (Beeton and Chandy, 2005; Rangaraju et al., 2009). Although Kv1.3 activity determines the level of leukocyte activation, this may be conditioned by the presence of other Kv1 isoforms and their association with accessory subunits (Beeton and Chandy, 2005; Vicente et al., 2005a).

Lymphocytes express several Kv currents ( $n$-, $n^{\prime}$ - and $l$-type channels). While the type $n$ channel is the most commonly observed $\mathrm{K}^{+}$ channel in normal T-lymphocytes, the subtype $l$ has a larger singlechannel conductance, and the $n^{\prime}$ channel has biophysical and pharmacological properties similar to those of the $n$ channel but is more resistant to block by tetraethylammonium (TEA) (Grissmer et al., 1992). Whereas Kv1.3 is associated with the $n$-type channel and Kv3.1 seems to account for the $l$-type, the protein responsible for the $n^{\prime}$-type is uncertain (Grissmer et al., 1992; Cahalan and Chandy, 1997). In addition, other channel proteins have been described in immune system cells. Kv1.1 is present in $\mathrm{CD}^{-}{ }^{-} \mathrm{CD} 8^{-}$thymocytes, and the presence of Kv1.1, Kv1.2, and Kv1.6 has been documented in naïve CD4 ${ }^{+}$ lymphocytes (Liu et al., 2002). In addition, several regulatory subunits may tune Kv currents resembling different entities. Thus, classical Kv $\beta$ subunits are present in lymphocytes and macrophages (Autieri et al., 1997; Vicente et al., 2005a). Furthermore, other types of modulatory subunits, such as KCNEs, are also present in leukocytes (Sole et al., 2009; Sole and Felipe, 2010). For example, KCNE1 was cloned from T-cells (Attali et al., 1992), and KCNE4 is expressed in macrophages (Sole et al., 2009). In this scenario deciphering the composition of channel structures that include channel subunits and regulatory proteins (channelosome) in leukocytes is worth of effort.

In addition, pharmacological studies in lymphocytes as well as in macrophages have demonstrated that the blockage of the $\mathrm{K}^{+}$ outward current by $\mathrm{K}^{+}$channel-blockers, such as charybdotoxin, TEA and 4-Aminopyridine (4-AP) reveals other components. These components have more depolarized thresholds for activation, absence of inactivation under sustained depolarized pulses and negligible cumulative inactivation (Ypey and Clapham, 1984; Decoursey et al., 1987; Verheugen and Korn, 1997). Although the presence of Kv3.1 could somehow explain these features, Kv1.5 may be an alternative candidate (Grissmer et al., 1992; Verheugen and Korn, 1997; Vicente et al., 2003, 2005a).

\section{DIFFERENTIAL FEATURES OF Kv1.3 AND Kv1.5}

Kv1.3, the major leukocytic Kv channel, and Kv1.5 show characteristic features that clearly differentiate both proteins.

Kv1.3 (KCNA3) is a voltage-gated $\mathrm{K}^{+}$channel that was cloned in brain, but it is highly present in lymphocytes and olfactory bulb (Stuhmer et al., 1989). However, recent works have demonstrated that it is more widely expressed, especially in skeletal muscle and epithelia (Bielanska et al., 2009). Kv1.3 exhibits marked C-type and cumulative inactivation. The single-channel conductance of $\mathrm{Kv} 1.3$ is about $13 \mathrm{pS}$, and the $\mathrm{V}_{h}$ for activation is around $-35 \mathrm{mV}$. In addition, Kv1.3 has a number of specific blockers. Thus, scorpion toxins, such as charybdotoxin (Leiurus quinquestriatus hebraeus) and margatoxin (Centruroides margaritatus) as well as sea anemone peptides, such as Shk (Stichodactyla helianthus) and their derivatives, have proven to be highly effective. Furthermore, there are several Kv1.3 chemical inhibitors, such as the potent 5-(4-phenylbutoxy) psoralen (Psora-4) (Vennekamp et al., 2004)1.

Kv1.5 (KCNA5) shows characteristics typical of voltage-gated $\mathrm{K}^{+}$ channels in cardiac myocytes. It was cloned from rat brain (Swanson et al., 1990), although the distribution is more ubiquitous than previously thought (Bielanska et al., 2009). Kv1.5 contributes to the ultrarapid activating $\mathrm{K}^{+}$current in heart $\left(\mathrm{IK}_{u r}\right)$, but it is also involved in myoblast proliferation and cell volume control (Felipe et al., 1993; Villalonga et al., 2008). Kv1.5 conductance is $8 \mathrm{pS}$, and the $\mathrm{V}_{h}$ for activation is approximately $14 \mathrm{mV}$. In addition, Kv1.5 inactivates very slowly $(\tau>5 \mathrm{~s})$ and lacks cumulative inactivation. Kv1.5, which is highly insensitive to Kv1.3 blockers, has no known specific pharmacology. However, this is currently under intensive investigation. Current research indicates that Kv1.5, similar to Kv1.3, is inhibited

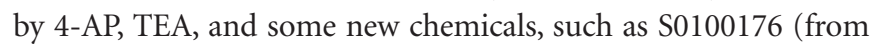
Sanofi-Aventis) or diphenyl phosphine oxide-1 (DPO-1) (Decher et al., 2004; Villalonga et al., 2008; Du et al., 2010)².

\section{Kv1.5 IN THE IMMUNE SYSTEM}

Pioneer work conducted during the 1970s by Gallin and coworkers described the first $\mathrm{K}^{+}$currents in peritoneal macrophages (Gallin et al., 1975; Gallin and Gallin, 1977; Gallin and Livengood, 1980). Later, this $\mathrm{K}^{+}$outward conductance was characterized in both lymphocytes and macrophages (Gallin, 1981, 1984; Ypey and Clapham, 1984; Decoursey et al., 1987). Although delayed rectifier $\mathrm{K}^{+}$currents are similar in both cell types, Kv1.5 was soon detected in microglia (brain macrophages) (Pyo et al., 1997; Jou et al., 1998). These early works suggested that Kv1.5 plays an important role in the immune system. However, elicited currents showed certain C-type inactivation, which is absent in Kv1.5. In addition, Kv1.3 blockers, such as Charybdotoxin, were used to pharmacologically characterize the current in macrophages (Kim et al., 1996). However, this apparent discrepancy could be explained by the cellular models analyzed (Table 1). These works mostly analyzed peritoneal elicited macrophages, and under these experimental conditions, cells were isolated upon intraperitoneal injection (Gallin and Livengood, 1980; Ypey and Clapham, 1984). Currently, we know that Kv1.3 and Kv1.5 are subject to differential regulation (Vicente et al., 2006; Villalonga et al., 2010a). Under activation conditions, unlike Kv1.5, Kv1.3 is selectively activated. Any study in activated cells would underestimate the Kv1.5dependent component of the outward $\mathrm{K}^{+}$current. Later works from Eder and coworkers demonstrated that, unlike T-cells, resting bone marrow-derived macrophages express less inactivating outward $\mathrm{K}^{+}$ currents, which are selectively induced by specific growth factors (Eder and Fischer, 1997). These more recent reports suggested that notable differences exist between T-lymphocytes and macrophages. In 2003, we published a complete biophysical, pharmacological and molecular characterization of the Kv1 channels present in macrophages (Vicente et al., 2003). Although pharmacological experiments

${ }^{1}$ http://www.iuphar-db.org/iuphar-ic/KV/KV13.pdf ${ }^{2}$ http://www.iuphar-db.org/iuphar-ic/KV/KV15.pdf 





suggested that Kv1.3 is predominant, Kv1.5 is also present in the myeloid lineage. Furthermore, cell activation selectively increases Kv1.3 activity, and these phenotypical changes are under tight transcriptional, translational, and post-translational controls in macrophages, which may implicate hetero-oligomeric associations in the macrophage channelosome (Vicente et al., 2006).

During the same time frame, Mackenzie et al. (2003) described that human alveolar macrophages only express Kv1.3, with no other $\mathrm{Kv1}$ isoforms. However, because $\mathrm{MgTx}(1 \mathrm{nM})$ does not abrogate Fc receptor-mediated phagocytosis, the authors suggested that although Kv1.3 sets the resting membrane potential, it is not required for phagocytosis. The debate intensified when Park et al. (2006), using a similar experimental model, concluded that Kv1.5, but not Kv1.3, plays a pivotal role in human alveolar macrophages.

A common feature of all these studies is the sensitivity of $\mathrm{K}^{+}$ currents to some blockers such as MgTx, 4-AP, TEA, or Shk-Dap ${ }^{22}$. Several works also tried to abrogate $\mathrm{K}^{+}$currents by incubating with antisense oligonucleotides and adenovirus, and differing results have indicated possible roles for both proteins in the immune physiology (Chung et al., 2001; Mullen et al., 2006; Pannasch et al., 2006). Therefore, for the first time, a new putative role for the Kv1.5 channel in the immune system was highlighted in a comprehensive review (Judge et al., 2006). In 2006, the field took an important step forward. Several laboratories identified shared expression of both Kv1.3 and Kv1.5 proteins in the myeloid lineage (Mullen et al., 2006; Pannasch et al., 2006; Park et al., 2006; Vicente et al., 2006). Thus, both channels were found to modulate distinct functions in microglia, dendritic cells, and macrophages. However, the precise mechanism was still under debate (Fordyce et al., 2005). The initial evidence of heterotetrameric associations was suggested 1 year previously (Vicente et al., 2005b). These reports led many laboratories to the hypothesis that Kv1.3 and Kv1.5 could interact, forming a heterotetrameric functional channel.

Subsequent work performed in our laboratory unequivocally demonstrated that both proteins heteromerize in macrophages (Vicente et al., 2006; Villalonga et al., 2007; Villalonga et al., 2010a). Specifically, our results revealed that the functional heteromeric complex shows different sensitivity to Kv1.3 blockers and exhibits biophysical features accounted for by a variable tetrameric protein ratio.

\section{PHYSIOLOGICAL ROLE OF THE HETEROTETRAMERIC CHANNEL IN THE IMMUNE SYSTEM}

With few exceptions, most laboratories find that microglia, macrophages, and dendritic cells, all from the myeloid lineage, coexpress Kv1.5 and Kv1.3. In addition, many studies demonstrated that both proteins are involved in leukocyte physiology in some way. The question of to what extent Kv1.5 controls the immune function remains. Arguments both against and in favor of a crucial role for Kv1.5 in the immune system have been presented. However, the answer could be the variable composition of a tetramer (Vicente et al., 2006; Villalonga et al., 2007, 2010a) (Figure 1). Similar arguments are valid for many $\mathrm{K}^{+}$channels in the cardiovascular and nervous systems (Roden et al., 2002; Vacher et al., 2008).

Membrane potential of leukocytes ranges from -30 to $-60 \mathrm{mV}$ (Rink et al., 1980; Mello de Queiroz et al., 2008). Kv1.3 has a $V_{1 / 2}$ for activation of $-35 \mathrm{mV}$, and this value is in a physiological range.

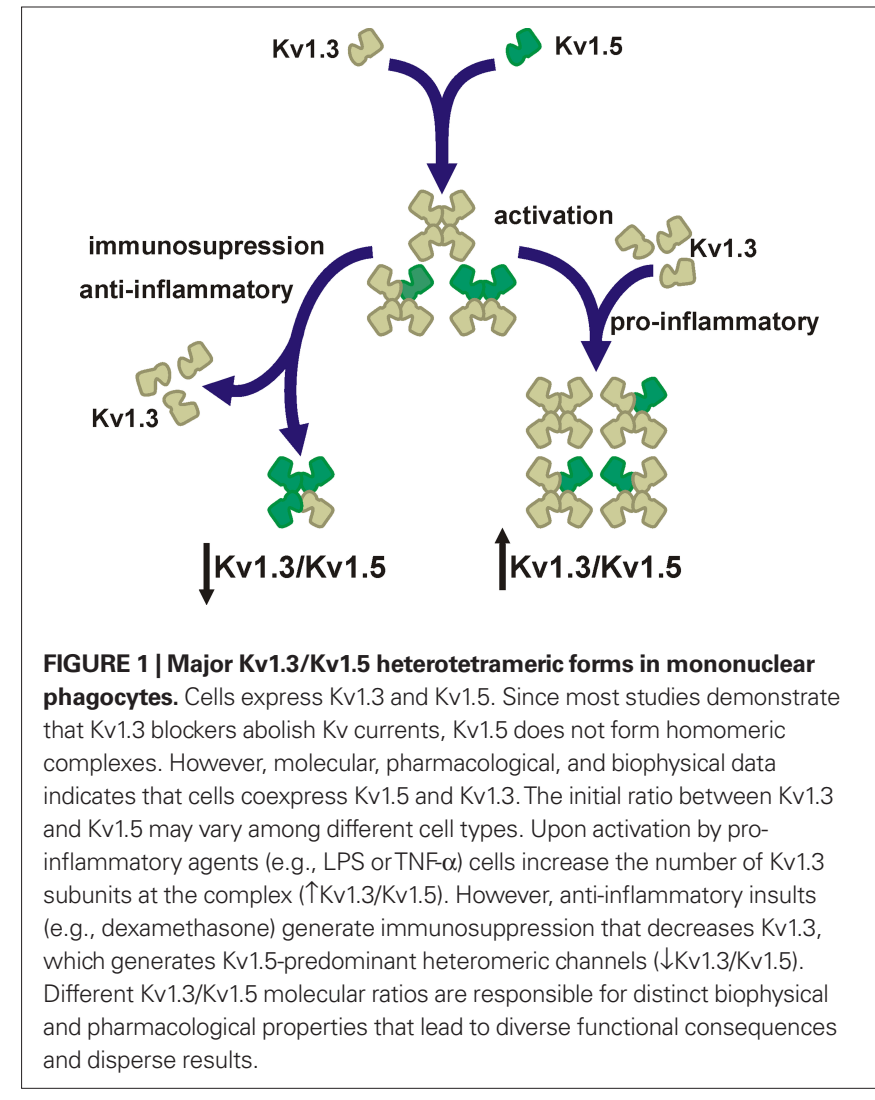

Under such conditions, Kv1.5 would be inefficient because it has a depolarized $V_{1 / 2}$ for activation (14 mV) (Table 1). Furthermore, the pharmacology of Kv1.3 blockers indicates that whereas Kv1.3 may exist as homotetramers, Kv1.5 never forms functional homomeric channels (Villalonga et al., 2007, 2010a). In this scenario, functional complexes formed by high $\mathrm{Kv} 1.3 / \mathrm{Kv} 1.5$ ratios would exhibit biophysical and pharmacological characteristics that closely resemble Kv1.3 homomers (Vicente et al., 2006, 2008). However, functional complexes generated by low Kv1.3/Kv1.5 ratios would exhibit biophysical characteristics closely related to Kv1.5, but the pharmacology of the channel, although limited, would be still sensitive to Kv1.3 blockers (Vicente et al., 2006, 2008).

Different hetero-oligomeric ratios trigger a plethora of functional complexes with different characteristics (Figure 1). The Kv1.3/Kv1.5 ratio, which would resemble Kv1.3-like to Kv1.5-like homomeric channels, would have important physiological consequences. In addition, these ratios may vary upon the physiological situation. Recent reports from our laboratory explore this issue (Vicente et al., 2006; Villalonga et al., 2007, 2010a). While LPS (lipopolysaccharide) or TNF- $\alpha$-activated macrophages increase the number of Kv1.3 subunits at the complex, dexamethasone, a potent glucocorticoid which abrogates the immune response, down-regulates Kv1.3 and raises the Kv1.5 units in the heteromeric channel (Villalonga et al., 2010a). In this situation, biophysical, and pharmacological characteristics resemble Kv1.5 (Figure 1). Therefore, the pharmacology of Kv1.3/Kv1.5 hybrid channels, with high Kv1.5 ratio, is more resistant to Kv1.3 blockers, and 
more importantly, the threshold for activation of heteromeric channels depolarizes (Vicente et al., 2006). At physiological membrane potentials ( -30 to $-60 \mathrm{mV}$ ), Kv1.3/Kv1.5 (low Kv1.3 ratio) channel activity is impaired. Because negative potentials, contributed by $\mathrm{Kv} 1.3$, should open CRAC $\left(\mathrm{Ca}^{2+}\right.$ release-activated $\mathrm{Ca}^{2+}$ ) channels leading to further activating signals (Cahalan and Chandy, 2009), this scenario triggers immunosuppression and anti-inflammatory effects (Villalonga et al., 2010a,b). A similar situation has been described in B-lymphocytes where $a+25 \mathrm{mV}$ shift in the membrane potential negatively modulates the capability of B-cell producing antibodies (Freedman et al., 1992). Analogous results were obtained when two different macrophage cell lines were studied, such that macrophages that had higher Kv1.3/Kv1.5 ratios were more sensitive to Kv1.3-blockers, indicating that the physiological response is under Kv1.3 antagonist control (Villalonga et al., 2007). Similar phenotypical changes are produced during human dendritic cell maturation, which suggest that this is a general feature of Kv1.3/Kv1.5 expressing leukocytes (Zsiros et al., 2009).

\section{Kv1.5 LOCALIZATION IN THE IMMUNE SYSTEM}

Another unresolved but important issue concerns to what extent the Kv1.3/Kv1.5 heterotetramerization affects the channelosome localization. Kv1.3 forms part of a macromolecular complex associated with the TCR (T-cell receptor) in lymphocytes. Kv1.3, together with $\mathrm{K}_{\mathrm{Ca}} 3.1$, generates the membrane potential that activates CRAC $\left(\mathrm{Ca}^{2+}\right.$-release-activated $\left.\mathrm{Ca}^{2+}\right)$ channel upon TCR activation (Panyi et al., 2004; Cahalan and Chandy, 2009). This event occurs within the so-called immunological synapse (IS) between the T-cell and the antigen presenting cell (Panyi et al., 2003, 2004; Toth et al., 2009; Krummel and Cahalan, 2010; Varga et al., 2010). The association of Kv1.3 and the TCR/CD3 receptor has been documented by FRET (fluorescence resonance energy transfer). In this vein, molecular interactions between Kv1.3 and $\beta 1$-integrin, and SAP-97 (synapse-associated protein 97) and Kv $\beta 2$ regulatory subunits has been also documented (Panyi et al., 2004, Cahalan and Chandy, 2009). This macromolecular complex is located in lipid rafts (Toth et al., 2009). Lipid rafts are microdomain platforms, rich in sphingolipids and cholesterol, where many signaling molecules and their targets converge. Many studies demonstrate that Kv1.3 channelosome concentrates in the T-cell IS, within lipid rafts, and the raft disruption impairs the immune response (Nicolaou et al., 2007; Pottosin et al., 2007; Toth et al., 2009). In addition, immobilizing Kv1.3 channels at the IS increases the $\mathrm{Ca}^{2+}$ signaling, raising the downstream signaling transduction pathways (Nicolaou et al., 2007).

Macrophages and dendritic cells are professional antigen presenting cells, and share the expression of Kv1.3 and Kv1.5 (Vicente et al., 2003; Villalonga et al., 2007; Zsiros et al., 2009). There is no information about the specific localization of the channelosome in these cells within the IS. However, it is tempting to speculate that some molecular aggregation similar to that observed in T-cells may exist. In this context, Kv1.5 localization in lipid raft is under debate (Martinez-Marmol et al., 2008). Ten years ago, Kv1.5 was the first ion channel detected in lipid rafts and caveolae (Martens et al., 2001). However, authors argued against a physical interaction between caveolins and this channel. Later, a ternary complex formed by caveolin 3, SAP97 (Synapse-associated protein 97) and Kv1.5 was discovered (Folco et al., 2004). However, evidence indicates that the channel localization is more complex than previously thought (Martinez-Marmol et al., 2008). The coexpression of caveolin (Cav1 and Cav3) and Kv1.5 triggers their association and places the channel within lipid rafts (McEwen et al., 2008). However, in native tissues, the presence of Kv1.5 in rafts is under debate (Eldstrom et al., 2006; Martinez-Marmol et al., 2008). Although heterologously expressed Kv1.5 is located in raft microdomains in HEK 293 and fibroblasts cells, the channel is not present in rafts in cardiomyoblasts, skeletal muscle myoblasts and macrophages (Martens et al., 2001; Eldstrom et al., 2006; Vicente et al., 2008). However, upon activation, high Kv1.3/Kv1.5 ratios in macrophage channels partially relocate Kv1.5 in rafts (MartinezMarmol et al., 2008). In this context, experimental evidence has suggested that the putative association of Kv1.5 with Kv1.3 and other partnership interactions with accessory proteins may influence the channelosome surface expression (Figure 2). In fact, different Kv1.3/Kv1.5 ratios influence oligomeric channel trafficking and locate functional heteromeric channels in different surface microdomains (Vicente et al., 2008).

\section{Kv1.5 REGULATORY PARTNERSHIP INTERACTIONS}

Although the Kv1.3/Kv1.5 association could be considered as a main regulatory mechanism that controls leukocyte excitability (at least in myeloid cells), alternative associations to accessory proteins must be contemplated. In this context, Kv1.5 may interact with most proteins that have been extensively studied with Kv1.3. For example, similar to Kv1.3, Kv1.5 has a PDZ domain at the C-terminus that

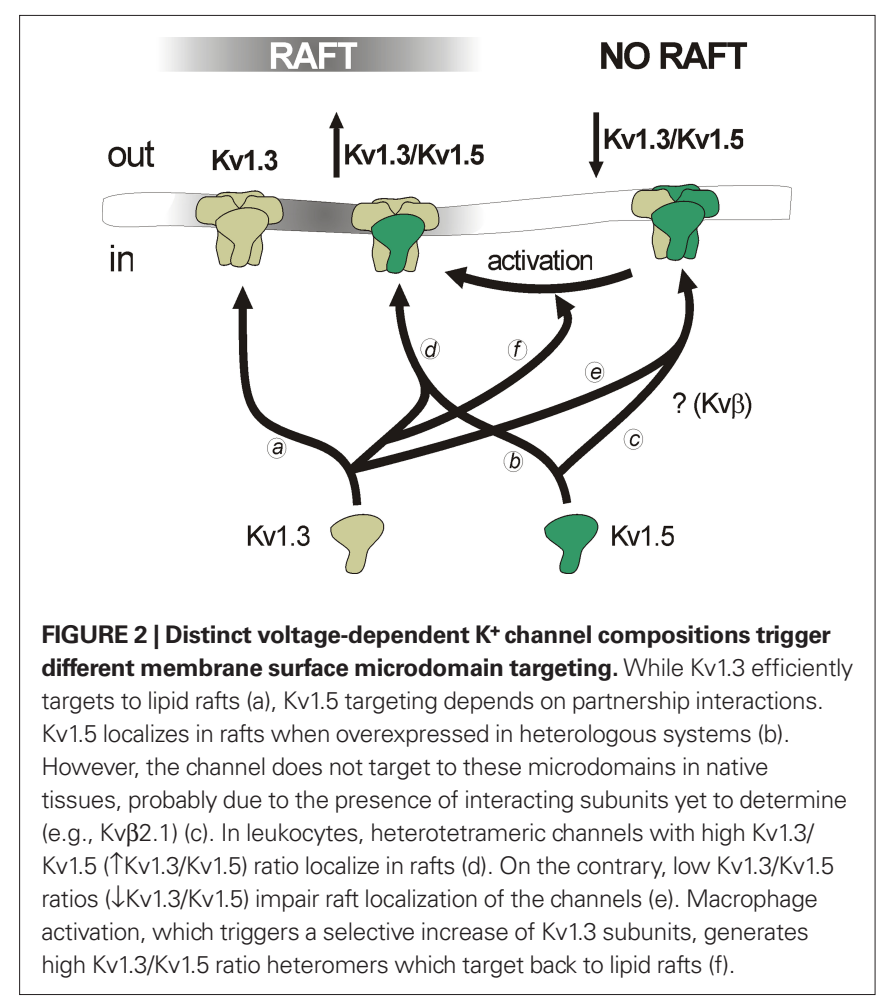


interacts with SAP97 (Murata et al., 2001; Eldstrom et al., 2003; AbiChar et al., 2008). In addition, Kv1.5 also interacts with members of KChiP ( $\mathrm{K}^{+}$channel-interacting proteins) family (Li et al., 2005). These interactions are known to modulate the surface expression of several $\mathrm{K}^{+}$channels, such as Kv4.2 (Shibata et al., 2003). Other possible candidates are the classical Kv $\beta$ subunits (Martens et al., 1999). These ancillary subunits, which are tightly modulated upon proliferation and the way of activation in macrophages, regulate Kv1.3 and Kv1.5 activity and may also control the channel expression at the membrane surface (Martens et al., 1999; Vicente et al., 2005a). In fact, the presence of the Kv $\beta 2.1$ subunit impairs the location of Kv1.5 in rafts, and this has been proposed to be the mechanism of how Kv1.5 colocalizes with caveolin in heterologous expression systems that lack $\mathrm{Kv} \beta$ expression but does not in native cells and tissues (Martinez-Marmol et al., 2008). Finally, new partnership associations with KCNE subunits have considerably increased the myriad of possibilities. For example, KCNE4 has been identified as a new dominant-negative Kv1.3 regulatory subunit that impairs channel activity, surface targeting, and traffic (Sole et al., 2009). In this context, KCNE2 seems to associate with mature forms of Kv1.5, triggering physiological consequences not yet fully understood (Roepke et al., 2008).

\section{REFERENCES}

Abi-Char, J., El-Haou, S., Balse, E., Neyroud, N., Vranckx, R., Coulombe, A., and Hatem, S. N. (2008). The anchoring protein SAP97 retains Kv1.5 channels in the plasma membrane of cardiac myocytes. Am. J. Physiol. Heart Circ. Physiol. 294, H1851-H1861.

Agarwal, J. R., Griesinger, F., Stühmer, W., and Pardo, L. A. (2010). The potassium channel Ether à go-go is a novel prognostic factor with functional relevance in acute myeloid leukemia. Mol. Cancer 9, 18.

Ashcroft, F. M. (2000). Ion Channels and Disease: Channelopathies. San Diego: Academic Press.

Attali, B., Romey, G., Honore, E., SchmidAlliana, A., Mattei, M. G., Lesage, F., Ricard, P., Barhanin, J., and Lazdunski, M. (1992). Cloning, functional expression, and regulation of two $\mathrm{K}^{+}$channels in human T lymphocytes. J. Biol. Chem. 267, 8650-8657.

Autieri, M. V., Belkowski, S. M., Constantinescu, C. S., Cohen, J. A., and Prystowsky, M. B. (1997). Lymphocyte-specific inducible expression of potassium channel beta subunits. J. Neuroimmunol. 77, 8-16.

Beeton, C., and Chandy, K. G. (2005). Potassium channels, memory T cells, and multiple sclerosis. Neuroscientist 11, 550-562.

Bielanska, J., Hernandez-Losa, J., PerezVerdaguer, M., Moline, T., Somoza, R., Ramon, Y.C.S., Condom, E., Ferreres, J. C., and Felipe, A. (2009). Voltagedependent potassium channels Kv1.3 and Kv1.5 in human cancer. Curr. Cancer Drug Targets 9, 904-914.

Cahalan, M.D., and Chandy, K. G. (1997). Ion channels in the immune system as targets for immunosuppression. Curr. Opin. Biotechnol. 8, 749-756.

Cahalan, M. D., and Chandy, K. G. (2009). The functional network of ion channels in T lymphocytes. Immunol. Rev. 231, 59-87.

Cahalan, M.D., Chandy, K. G., DeCoursey, T. E., and Gupta, S. (1985) A voltagegated potassium channel in human T lymphocytes. J. Physiol. 358, 197-237.

Cayabyab, F. S., Khanna, R., Jones, O. T., and Schlichter, L. C. (2000). Suppression of the rat microglia Kv1.3 current by src-family tyrosine kinases and oxygen/glucose deprivation. Eur. J. Neurosci. 12, 1949-1960.

Chung, S., Lee, J., Joe, E. H., and Uhm, D.Y. (2001). Beta-amyloid peptide induces the expression of voltage dependent outward rectifying $\mathrm{K}^{+}$channels in rat microglia. Neurosci. Lett. 300, 67-70.

Decoursey, T. E., Chandy, K. G., Gupta, S., and Cahalan, M. D. (1987). Two types of potassium channels in murine T lymphocytes. J. Gen. Physiol. 89, 379-404.

Decher, N., Pirard, B., Bundis, F., Peukert, S., Baringhaus, K. H., Busch, A. E., Steinmeyer, K., and Sanguinetti, M. C. (2004). Molecular basis for Kv1.5 channel block: conservation of drug binding sites among voltage-gated $\mathrm{K}^{+}$channels. J. Biol. Chem. 279, 394-400.

\section{CONCLUSION}

Although the voltage-dependent Kv1.3 channel is essential for the immune cell physiology increasing evidence indicate that Kv1.5 plays an important role fine tuning the immune response. Pharmacological and biophysical reports argue against homomeric Kv1.5 complexes, but hetero-oligomeric associations with Kv1.3 increase the possibilities for Kv channels in leukocytes. The identification of multiple heterotetrameric conformations and their membrane surface localization may bring to light a better use for $\mathrm{K}^{+}$channels as pharmacological targets in autoimmune diseases. Furthermore, in this scenario, the multiple regulatory subunit association to homo- and heteromeric channels in the immune system is revealed as an important mechanism for further study to enhance the current understanding of the role of Kv1.5 in the immune physiology.

\section{ACKNOWLEDGMENTS}

The authors thank to all present and past members of the Molecular Physiology (MP) laboratory. Work from the MP lab supported by the Ministerio de Ciencia e Innovación (MICINN), Spain (BFI2002-00764, BFU2005-00695, BFU2008-00431, and CSD2008-00005 to Antonio Felipe; BFU2006-06076 and BFU2009-07501 to Concepció Soler). Núria Comes is supported by the Juan de la Cierva program (MICINN).

Du, Y. M., Zhang, X. X., Tu, D. N., Zhao, N., Liu, Y. J., Xiao, H., Sanguinetti, M. C., Zou, A., and Liao, Y. H. (2010). Molecular determinants of Kv1.5 channel block by diphenyl phosphine oxide-1. J. Mol. Cell Cardiol. 48, 1111-1120.

Eder, C. (1998). Ion channels in microglia (brain macrophages). Am. J. Physiol. 275, C327-C342.

Eder, C., and Fischer, H. G. (1997) Effects of colony-stimulating factors on voltage-gated $\mathrm{K}^{+}$currents of bone marrow-derived macrophages. Naunyn Schmiedebergs Arch. Pharmacol. 355, 198-202.

Eder, C., Fischer, H. G., Hadding, U., and Heinemann, U. (1995). Properties of voltage-gated currents of microglia developed using macrophage colonystimulating factor. Pflugers Arch. 430, 526-533.

Eldstrom, J., Choi, W. S., Steele, D. F., and Fedida, D. (2003). SAP97 increases Kv1.5 currents through an indirect N-terminal mechanism. FEBS Lett. 547, 205-211.

Eldstrom, J., Van Wagoner, D. R., Moore, E. D., and Fedida, D. (2006). Localization of Kv1.5 channels in rat and canine myocyte sarcolemma. FEBS Lett. 580, 6039-6046.

Fischer, H.G., and Eder, C. (1995) Voltagegated $\mathrm{K}^{+}$currents of mouse dendritic cells. FEBS Lett. 373, 127-130.

Felipe, A., Snyders, D. J., Deal, K. K., and Tamkun, M. M. (1993). Influence of cloned voltage-gated $\mathrm{K}^{+}$channel expression on alanine transport, $\mathrm{Rb}^{+}$ uptake, and cell volume. Am. J. Physiol. 265, C1230-C1238.

Folco, E. J., Liu, G. X., and Koren, G. (2004). Caveolin-3 and SAP97 form a scaffolding protein complex that regulates the voltage-gated potassium channel Kv1.5. Am. J. Physiol. Heart Circ. Physiol. 287, H681-H690.

Fordyce, C. B., Jagasia, R., Zhu, X., and Schlichter, L. C. (2005). Microglia Kv1.3 channels contribute to their ability to kill neurons. J. Neurosci. 25, 7139-7149.

Freedman,B.D., Price, M.A., and Deutsch, C. J. (1992). Evidence for voltage modulation of IL-2 production in mitogen-stimulated human peripheral blood lymphocytes. J. Immunol. 149, 3784-3794.

Gallin, E. K. (1981).Voltage clamp studies in macrophages from mouse spleen cultures. Science 214, 458-460.

Gallin, E. K. (1984). Electrophysiological properties of macrophages. Fed. Proc. 43, 2385-2389.

Gallin, E. K., and Gallin, J. I. (1977). Interaction of chemotactic factors with human macrophages. Induction of transmembrane potential changes. J. Cell Biol. 75, 277-289.

Gallin, E. K., and Livengood, D. R. (1980). Nonlinear current-voltage relationships in cultured macrophages. J. Cell Biol. 85, 160-165.

Gallin, E. K., Wiederhold, M. L., Lipsky, P. E., and Rosenthal, A. S. (1975). Spontaneous and induced membrane hyperpolarizations in macrophages. J. Cell. Physiol. 86(Suppl. 2), 653-661. 
Grissmer, S., Ghanshani, S., Dethlefs, B., McPherson, J. D., Wasmuth, J. J., Gutman, G. A., Cahalan, M. D., and Chandy, K. G. (1992). The Shawrelated potassium channel gene, Kv3.1, on human chromosome 11, encodes the type $1 \mathrm{~K}^{+}$channel in T cells. J. Biol. Chem. 267, 20971-20979.

Grissmer, S., Nguyen, A. N., Aiyar, J., Hanson, D. C., Mather, R. J., Gutman, G. A., Karmilowicz, M. J., Auperin, D. D., and Chandy, K. G. (1994). Pharmacological characterization of five cloned voltage-gated $\mathrm{K}^{+}$ channels, types Kv1.1, 1.2, 1.3, 1.5, and 3.1, stably expressed in mammalian cell lines. Mol. Pharmacol. 45, 1227-1234.

Gutman, G. A., Chandy, K. G., Grissmer, S., Lazdunski, M., McKinnon, D., Pardo, L. A., Robertson, G. A., Rudy, B., Sanguinetti, M. C., Stuhmer, W., and Wang, X. (2005). International Union of Pharmacology. LIII. Nomenclature and molecular relationships of voltagegated potassium channels. Pharmacol. Rev. 57, 473-508.

Hille, B. (2001). Ion Channels of Excitable Membranes, 3rd Edn. Sunderland, MA: Sinauer.

Jou, I., Pyo, H., Chung, S., Jung, S. Y., Gwag, B. J., and Joe, E. H. (1998). Expression of $\mathrm{Kv} 1.5 \mathrm{~K}^{+}$channels in activated microglia in vivo. Glia 24 , 408-414.

Judge, S. I., Lee, J. M., Bever, C. T. Jr., and Hoffman, P. M. (2006). Voltage-gated potassium channels in multiple sclerosis: Overview and new implications for treatment of central nervous system inflammation and degeneration. J. Rehabil. Res. Dev. 43, 111-122.

Jurkat-Rott, K., Lerche, H., and LehmannHorn, F. (2002). Hereditary channelopathies in neurology. J. Neurol. 249, 1493-1502.

Jurkat-Rott, K., Lerche, H., Weber, Y., and Lehmann-Horn, F. (2010). Hereditary channelopathies in neurology. $A d v$. Exp. Med. Biol. 686, 305-334

Khanna, R., Roy, L., Zhu, X., and Schlichter, L. C. (2001). $\mathrm{K}^{+}$channels and the microglial respiratory burst. Am. J. Physiol., Cell Physiol. 280, C796-C806.

Kim, S. Y., Silver, M. R., and DeCoursey, T. E. (1996). Ion channels in human THP-1 monocytes. J. Membr. Biol. 152, 117-130.

Koni, P. A., Khanna, R., Chang, M. C., Tang, M. D., Kaczmarek, L. K., Schlichter, L. C., and Flavella, R. A. (2003). Compensatory anion currents in Kv1.3 channel-deficient thymocytes. J. Biol. Chem. 278, 39443-39451.

Kotecha, S. A., and Schlichter, L. C. (1999). A Kv1.5 to Kv1.3 switch in endogenous hippocampal microglia and a role in proliferation. J. Neurosci. 19, 10680-10693.

Krummel, M. F., and Cahalan, M. D. (2010). The immunological synapse: a dynamic platform for local signaling. J. Clin. Immunol. 30, 364-372.

Lehmann-Horn, F., and Jurkat-Rott K. (1999). Voltage-gated ion channels and hereditary disease. Physiol. Rev. 79, 1317-1372.

Li, H., Guo, W., Mellor, R. L., and Nerbonne, J. M. (2005). KChIP2 modulates the cell surface expression of Kv 1.5-encoded $\mathrm{K}^{+}$channels. J. Mol. Cell Cardiol. 39, 121-132.

Liu, Q.H., Fleischmann, B. K., Hondowicz, B., Maier, C. C., Turka, L. A., Yui, K., Kotlikoff, M. I., Wells, A. D., and Freedman, B.D. (2002). Modulation of $\mathrm{Kv}$ channel expression and function by TCR and costimulatory signals during peripheral $\mathrm{CD}^{+}{ }^{+}$lymphocyte differentiation. J. Exp. Med. 196, 897-909.

Mackenzie, A. B., Chirakkal, H., and North, R. A. (2003). Kv1.3 potassium channels in human alveolar macrophages. Am. J. Physiol. Lung Cell Mol. Physiol. 285, L862-L868.

Martens, J. R., Kwak, Y. G., and Tamkun, M.M. (1999). Modulation of Kv channel alpha/beta subunit interactions. Trends Cardiovasc. Med. 9, 253-258.

Martens, J. R., Sakamoto, N., Sullivan, S. A., Grobaski, T.D., and Tamkun, M.M. (2001). Isoform-specific localization of voltage-gated $\mathrm{K}^{+}$channels to distinct lipid raft populations. Targeting of Kv1.5 to caveolae. J. Biol. Chem. 276, 8409-8414.

Martinez-Marmol, R., Villalonga, N., Sole, L., Vicente, R., Tamkun, M. M., Soler, C., and Felipe, A. (2008). Multiple Kv1.5 targeting to membrane surface microdomains. J. Cell Physiol. 217, 667-673.

Matzner, N., Zemtsova, I. M., Nguyen, T. X., Duszenko, M., Shumilina, E., and Lang, F. (2008). Ion channels modulating mouse dendritic cell functions. J. Immunol. 181, 6803-6809.

McEwen, D. P., Li, Q., Jackson, S., Jenkins, P. M., and Martens, J. R. (2008). Caveolin regulates kv1.5 trafficking to cholesterol-rich membrane microdomains. Mol. Pharmacol. 73, 678-685.

Mello de Queiroz, F., Ponte, C.G., Bonomo, A., Vianna-Jorge, R., and Suarez-Kurtz, G. (2008). Study of membrane potential in T lymphocytes subpopulations using flow cytometry. BMC Immunol. 9, 63. doi: 10.1186/1471-2172-9-63.

Menteyne, A., Levavasseur, F., Audinat, E., and Avignone, E. (2009). Predominant functional expression of Kv1.3 by activated microglia of the hippocampus after Status epilepticus. PLoS One. 4, e6770. doi: 10.1371/journal. pone.0006770.
Mullen, K. M., Rozycka, M., Rus, H., Hu, L., Cudrici, C., Zafranskaia, E., Pennington, M. W., Johns, D. C., Judge, S. I., and Calabresi, P. A. (2006). Potassium channels Kv1.3 and Kv1.5 are expressed on blood-derived dendritic cells in the central nervous system. Ann. Neurol. 60, 118-127.

Murata, M., Buckett, P. D., Zhou, J., Brunner, M., Folco, E., and Koren, G. (2001). SAP97 interacts with Kv1.5 in heterologous expression systems. Am. J. Physiol. Heart Circ. Physiol. 281, H2575-H2584.

Nelson, D. J., Jow, B., and Jow, F. (1992). Lipopolysaccharide induction of outward potassium current expression in human monocyte-derived macrophages: lack of correlation with secretion. J. Membr. Biol. 125, 207-218.

Nelson, D. J., Jow, B., and Popovich, K. J. (1990) Whole-cell currents in macrophages: II. Alveolar macrophages. J. Membr. Biol. 117, 45-55.

Nicolaou, S. A., Szigligeti, P., Neumeier, L., Lee, S. M., Duncan, H. J., Kant, S. K., Mongey, A. B., Filipovich, A. H., and Conforti, L. (2007). Altered dynamics of Kv1.3 channel compartmentalization in the immunological synapse in systemic lupus erythematosus. J. Immunol. 179, 346-356.

Pannasch, U., Farber, K., Nolte, C. Blonski, M., Yan Chiu, S., Messing, A., and Kettenmann, H. (2006). The potassium channels Kv1.5 and Kv1.3 modulate distinct functions of microglia. Mol. Cell. Neurosci. 33, 401-411.

Panyi, G., Bagdany, M., Bodnar, A., Vamosi, G., Szentesi, G., Jenei, A., Matyus, L., Varga, S., Waldmann, T. A., Gaspar, R., and Damjanovich, S. (2003). Colocalization and nonrandom distribution of Kv1.3 potassium channels and CD3 molecules in the plasma membrane of human T lymphocytes. Proc. Natl. Acad. Sci. U.S.A. 100, 2592-2597.

Panyi, G., Vamosi, G., Bacso, Z., Bagdany, M., Bodnar, A., Varga, Z., Gaspar, R., Matyus, L., and Damjanovich, S. (2004). Kv1.3 potassium channels are localized in the immunological synapse formed between cytotoxic and target cells. Proc. Natl. Acad. Sci. U.S.A. 101, 1285-1290.

Panyi, G., Varga, Z., and Gaspar, R. (2004). Ion channels and lymphocyte activation. Immunol. Lett. 92, 55-66.

Park, S. A., Lee, Y. C., Ma, T. Z., Park, J. A., Han, M. K., Lee, H. H., Kim, H. G., and Kwak, Y. G. (2006). hKv1.5 channels play a pivotal role in the functions of human alveolar macrophages. Biochem. Biophys. Res. Commun. 346, 567-571.

Pillozzi, S., Brizzi, M. F., Balzi, M., Crociani, O., Cherubini, A., Guasti, L.,
Bartolozzi, B., Becchetti, A., Wanke, E., Bernabei, P. A., Olivotto, M., Pegoraro, L., and Arcangeli, A. (2002). HERG potassium channels are constitutively expressed in primary human acute myeloid leukemias and regulate cell proliferation of normal and leukemic hemopoietic progenitors. Leukemia 16, 1791-1798.

Pottosin, II, Valencia-Cruz, G., BonalesAlatorre, E., Shabala, S. N., and Dobrovinskaya, O. R. (2007). Methyl-beta-cyclodextrin reversibly alters the gating of lipid rafts-associated Kv1.3 channels in Jurkat Tlymphocytes. Pflugers Arch. 454, 235-244.

Pyo, H., Chung, S., Jou, I., Gwag, B., and Joe, E. H. (1997). Expression and function of outward $\mathrm{K}^{+}$channels induced by lipopolysaccharide in microglia. Mol. Cells 7, 610-614.

Rangaraju, S., Chi, V., Pennington, M. W. and Chandy, K. G. (2009). Kv1.3 potassium channels as a therapeutic target in multiple sclerosis. Expert Opin. Ther. Targets. 13, 909-924.

Rink, T. J., Montecucco, C., Hesketh, T. R., and Tsien, R. Y. (1980). Lymphocyte membrane potential assessed with fluorescent probes. Biochim. Biophys. Acta 595, 15-30.

Roden, D. M., Balser, J. R., George, A. L., Jr., and Anderson, M. E. (2002). Cardiac ion channels. Annu. Rev. Physiol. 64, 431-475.

Roepke, T. K., Kontogeorgis, A., Ovanez, C., Xu, X., Young, J. B., Purtell, K., Goldstein, P. A., Christini, D. J., Peters, N. S., Akar, F. G., Gutstein, D. E., Lerner, D. J., and Abbott, G. W. (2008). Targeted deletion of kcne2 impairs ventricular repolarization via disruption of I (K,slow1) and I (to,f). FASEB J. 22, 3648-3660.

Sanguinetti, M. C., and Tristani-Firouzi, M. (2006). hERG potassium channels and cardiac arrhythmia. Nature 440 , 463-469.

Schilling, T., Quandt, F. N., Cherny, V. V., Zhou, W., Heinemann, U., Decoursey, T. E., and Eder, C. (2000). Upregulation of $\mathrm{Kv1} .3 \mathrm{~K}(+)$ channels in microglia deactivated by TGFbeta. Am. J. Physiol. Cell Physiol. 279, C1123-C1134.

Shibata, R., Misonou, H., Campomanes, C. R., Anderson, A. E., Schrader, L. A. Doliveira, L. C., Carroll, K. I., Sweatt, J. D., Rhodes, K. J., and Trimmer, J. S. (2003). A fundamental role for KChIPs in determining the molecular properties and trafficking of Kv4.2 potassium channels. J. Biol. Chem. 278, 36445-36454.

Smith, G. A., Tsui, H. W., Newell, E. W., Jiang, X., Zhu, X. P., Tsui, F. W., and Schlichter, L. C. (2002). Functional up-regulation of HERG $\mathrm{K}^{+}$channels 
in neoplastic hematopoietic cells. J. Biol. Chem. 277, 18528-18534.

Sole, L., and Felipe, A. (2010). Does a physiological role for KCNE subunits exist in the immune system? Commun. Integr. Biol. 3, 166-168.

Sole,L., Roura-Ferrer,M.,Perez-Verdaguer, M., Oliveras, A., Calvo, M., FernandezFernandez, J. M., and Felipe, A. (2009). KCNE4 suppresses Kv1.3 currents by modulating trafficking, surface expression and channel gating. J. Cell Sci. 122, 3738-3748.

Stuhmer, W., Ruppersberg, J. P., Schroter, K. H., Sakmann, B., Stocker, M., Giese, K. P., Perschke, A., Baumann, A., and Pongs, O. (1989). Molecular basis of functional diversity of voltage-gated potassium channels in mammalian brain. ЕMBO J. 8, 3235-3244.

Swanson, R., Marshall, J., Smith, J. S., Williams, J. B., Boyle, M. B., Folander, K., Luneau, C. J., Antanavage, J., Oliva, C., Buhrow, S. A., Bennet, C., Stein, R. B., and Kaczmarek, L. K. (1990). Cloning and expression of cDNA and genomic clones encoding three delayed rectifier potassium channels in rat brain. Neuron 4, 929-939.

Toth, A., Szilagyi, O., Krasznai, Z., Panyi, G., and Hajdu, P. (2009). Functional consequences of Kv1.3 ion channel rearrangement into the immunological synapse. Immunol. Lett. 125, 15-21.

Vacher,H., Mohapatra, D.P., and Trimmer, J.S. (2008). Localization and targeting of voltage-dependent ion channels in mammalian central neurons. Physiol. Rev. 88, 1407-1447.

Varga, Z., Hajdu, P., and Panyi, G. (2010). Ion channels in T lymphocytes: an update on facts, mechanisms and therapeutic targeting in autoimmune diseases. Immunol. Lett. 130, 19-25.

Vennekamp, J., Wulff, H., Beeton, C., Calabresi, P. A., Grissmer, S., Hansel, W., and Chandy, K. G. (2004). Kv1.3blocking 5-phenylalkoxypsoralens: a new class of immunomodulators. Mol. Pharmacol. 65, 1364-1374.

Verheugen, J. A., and Korn, H. (1997). A charybdotoxin-insensitive conductance in human $\mathrm{T}$ lymphocytes: $\mathrm{T}$ cell membrane potential is set by distinct $\mathrm{K}^{+}$channels. J. Physiol. (Lond.) 503, 317-331.

Vicente, R., Escalada, A., Coma, M., Fuster, G., Sanchez-Tillo, E., Lopez-Iglesias, C., Soler, C., Solsona, C., Celada, A., and Felipe, A. (2003). Differential voltage-dependent $\mathrm{K}^{+}$channel responses during proliferation and activation in macrophages. J. Biol. Chem. 278, 46307-46320.

Vicente, R., Escalada, A., Soler, C., Grande, M., Celada, A., Tamkun, M. M., Solsona, C., and Felipe, A. (2005a). Pattern of Kv beta subunit expression in macrophages depends upon proliferation and the mode of activation. J. Immunol. 174, 4736-4744.

Vicente, R., Escalada, A., Villalonga, N., Texido, L., Roura-Ferrer, M., MartinSatue, M., Soler, C., Tamkun, M. M., Solsona, C., and Felipe, A. (2005b). Does Kv1.5 have a physiological role in the main voltage-dependent $\mathrm{K}^{+}$current in macrophages? J. Physiol. Biochem. 61, 61-62.

Vicente, R., Escalada, A., Villalonga, N., Texido, L., Roura-Ferrer, M., MartinSatue, M., Lopez-Iglesias, C., Soler, C., Solsona, C., Tamkun, M. M., and Felipe, A. (2006). Association of $\mathrm{Kv} 1.5$ and $\mathrm{Kv} 1.3$ contributes to the major voltage-dependent $\mathrm{K}^{+}$channel in macrophages. J. Biol. Chem. 281, 37675-37685.

Vicente, R., Villalonga, N., Calvo, M., Escalada, A., Solsona, C., Soler, C., Tamkun, M. M., and Felipe, A. (2008) Kv1.5 association modifies Kv1.3 traffic and membrane localization. J. Biol. Chem. 283, 8756-8764.

Villalonga, N., David, M., Bielanska, J., Vicente, R., Comes, N., Valenzuela, C., and Felipe, A. (2010a). Immunomodulation of voltage-dependent $\mathrm{K}^{+}$channels in macrophages: molecular and biophysical consequences. J. Gen Physiol. 135, 135-147.

Villalonga, N., David, M., Bielańska, J., González, T., Parra, D., Soler, C., Comes, N., Valenzuela, C., and Felipe, A. (2010b). Immunomodulatory effects of diclofenac in leukocytes through the targeting of Kv1.3 voltage-dependent potassium channels. Biochem. Pharmacol. 80, 858-866.

Villalonga, N., Escalada, A., Vicente, R., Sanchez-Tillo, E., Celada, A., Solsona, C., and Felipe, A. (2007). Kv1.3/Kv1.5 heteromeric channels compromise pharmacological responses in macrophages. Biochem. Biophys. Res. Commun. 352, 913-918.

Villalonga, N., Martinez-Marmol, R., Roura-Ferrer, M., David, M., Valenzuela, C., Soler, C., and Felipe, A. (2008). Cell cycle-dependent expression of Kv1.5 is involved in myoblast proliferation. Biochim. Biophys. Acta. 1783, 728-736.

Xuan, N. T., Shumilina, E., Matzner, N., Zemtsova, I. M., Biedermann, T.,
Goetz, F., and Lang, F. (2009). $\mathrm{Ca}^{2+}$ dependent functions in peptidoglycan-stimulated mouse dendritic cells. Cell. Physiol. Biochem. 24, 167-176.

Ypey, D. L., and Clapham, D. E. (1984). Development of a delayed outwardrectifying $\mathrm{K}^{+}$conductance in cultured mouse peritoneal macrophages. Proc. Natl. Acad. Sci. U.S.A. 81, 3083-3087.

Zsiros, E., Kis-Toth, K., Hajdu, P., Gaspar, R., Bielanska, J., Felipe, A., Rajnavolgyi, E., and Panyi,G. (2009).Developmental switch of the expression of ion channels in human dendritic cells. $J$. Immunol. 183, 4483-4492.

Conflict of Interest Statement: The authors declare that the research was conducted in the absence of any commercial or financial relationships that could be construed as a potential conflict of interest.

Received: 08 September 2010; paper pending published:24September 2010; accepted: 28 October 2010; published online: 16 November 2010.

Citation: Felipe A, Soler C and Comes $N$ (2010) Kv1.5 in the immune system: the good, the bad, or the ugly? Front. Physio. 1:152. doi: 10.3389/fphys.2010.00152

This article was submitted to Frontiers in Membrane Physiology and Biophysics, a specialty of Frontiers in Physiology.

Copyright $\odot 2010$ Felipe, Soler and Comes. This is an open-access article subject to an exclusive license agreement between the authors and the Frontiers Research Foundation, which permits unrestricted use, distribution, and reproduction in any medium, provided the original authors and source are credited. 